\title{
Jornalismo para crianças: um serviço público da televisão portuguesa
}

\author{
ANELISE Schütz DiAS \\ Universidade Federal de Santa Maria - anelisesdias@gmail.com \\ Estudante de graduação do Departamento de Ciências da \\ Comunicação da Universidade Federal de Santa Maria. \\ GABRIELA BORGES \\ Universidade do Algarve - gaborges@ualg.pt \\ Mestre e doutora em Comunicação e Semiótica pela PUC-SP. Foi investigadora \\ visitante na Universidade Autônoma de Barcelona e no Trinity College Dublin. \\ Pesquisadora convidada do Centro de Investigação em Artes e \\ Comunicação na Universidade do Algarve, onde também \\ leciona nos cursos de Mestrado e Doutorado em Comunicação, Cultura \\ e Artes e Pós-Graduação em Artes Visuais e Performativas.
}

\begin{abstract}
Resumo
A televisão pública tem como objetivo oferecer programação baseada em conteúdos que se diferenciem dos da programação comercial. Deve obedecer a parâmetros de qualidade e servir à sociedade. Em Portugal, o segundo canal da Rádio e Televisão Portuguesa, RTP2, tem o dever de informar, de ajudar a preservar as garantias democráticas, além de divulgar ações culturais, sociais e políticas e reforçar laços identitários, através de uma perspectiva plural e diversa. Para o público infantil e infanto-juvenil, o canal aposta, com o Diário XS, em um formato inovador: um telejornal, de linguagem acessível, dedicado a informar os pequenos sobre o mundo que os cerca.
\end{abstract}

\section{Palavras-chave}

Jornalismo Infantil, RTP2, Diário XS

\begin{abstract}
The objective of public television is to offer a program schedule based in contents that differ from commercial programming. It has to obey quality parameters and serve the society. In Portugal, the Radio e Televisão Portuguesa second channel, RTP2, aims to inform, preserve democratic values as well to disseminate cultural, social and political actions, strengthening bonds identity, through a plural and diverse perspective. For the child/juvenile audience, the channel stake, with Diário XS, in a innovative format: a TV newscast, with accessible language, dedicated to educate and inform children about the world around them.
\end{abstract}

\section{Keywords}

Children Journalism, RTP2, Diário XS

Artigo recebido em 09/09/2012

Aprovado em 24/10/2012 
A programação é entendida como um fluxo contínuo e não como um mero catálogo de programas. Este fluxo é pensado e definido estrategicamente em função do conteúdo das emissões, dos dias, das horas e da época de emissão, dos recursos disponíveis para adquirir programas, dos hábitos, gostos e características sociodemográficas dos telespectadores e das grelhas de programação de outros canais.

(PEREIRA, Sara. A minha TV é um mundo, p.12)

Ainda que muitos investigadores privilegiem uma abordagem de dimensão técnica sobre a televisão, é preciso que os estudos televisivos levem em conta a dimensão e o alcance social desse meio, pois esse não é só um mero aparato tecnológico. É, segundo McQuail (1994), o palco da vida pública, no qual são representados e, ao mesmo tempo, construídos valores e comportamentos sociais.

Instalada no ambiente doméstico, a televisão também se insere na esfera privada e configura as relações interpessoais através da veiculação de conteúdos que influenciam na percepção de mundo dos agentes sociais e também na forma com que estes se reconhecem e representam a si mesmos nos grupos em que estão inseridos.

Alguns estudiosos, que vão além do tecnicismo, criticam a decadência em qualidade da TV dos nossos dias. Julgam que os canais estão preocupados em ampliar a audiência a qualquer preço e, por isso, acabam por negligenciar a qualidade da programação.

De acordo com Bustamante, as emissoras tomaram para si características próprias do marketing e as aplicaram na distribuição de gêneros, horários e públicosalvo na grade de programação. Além disso, houve a inserção de peças publicitárias, que agora disputam o espaço com a informação. "Face à concorrência existente, as televisões, inclusive as públicas, viram-se obrigadas a aumentar sua dependência de publicidade, o que condicionou sua programação" (BUSTAMANTE apud PEREIRA, p.15, 2007).

Do outro lado das câmeras, parte da opinião pública acusava a televisão de não ser o espelho da realidade social, mas sim uma distorção dela. Como espectadores, não se percebiam representados na programação oferecida. Por essa razão - dentre tantas outras, como a necessidade da democratização do acesso aos meios de comunicação e de divulgação cultural, da construção participativa da representação social na televisão e do acesso ao direito de cidadania que tange à informação e que se aplica aos conteúdos 
Estudos em Jornalismo e Mídia - Vol. 9 NN$^{\circ} 2$ - Julho a Dezembro de 2012 ISSNe 1984-6924

gerados, veiculados e consumidos - foram criadas as televisões públicas, que devem se estruturar a partir de uma série de parâmetros de qualidade complementares aos princípios básicos do serviço público.

Porém, há uma parcela importante de espectadores - as crianças - que, devido à sua faixa etária e representatividade social, é pouco considerada nas discussões acerca da qualidade da programação pelas televisões comerciais. Por conta de diversos processos históricos e pelas características da vida moderna, a televisão passou a ocupar mais espaço na vida desse grupo e se constituiu como instituição de influência, de mediação da realidade e de socialização. Conforme Pereira:

esse meio de comunicação assume um espaço-tempo relevante no quotidiano das crianças; conta-lhes histórias, faz apelo à sua fantasia e imaginação, mostralhes acontecimentos, pessoas e lugares a que dificilmente teriam acesso de outro modo, permitindo-lhes viajar no tempo e no espaço. (2002, p.11)

Já na televisão pública portuguesa, a criança, como cidadã, faz parte do público que deve ser considerado na produção de conteúdos que têm como foco a cultura, a investigação, a inovação, a ciência, a ação social, o desporto amador, os direitos e os deveres de cidadania, conforme as obrigações impostas pela Lei de Televisão $\mathrm{n}^{\mathbf{0}}$ 32/2003, de Portugal.

Borges (2011), baseado na obra Televisão e Cidadania, organizada por Manuel Pinto, elenca as funções do serviço público de televisão, que também deveriam ser incorporadas pela RTP2. As funções, de acordo com ele, são: preservação das garantias democráticas, informativa, cultural, educativa, divulgação social, política, interrelacional, identitária, mobilização dos valores, equilíbrio territorial, interatividade, estímulo à participação sócio-cultural e diversidade.

De concessão pública e de acordo com as funções que lhe são atribuídas e com as leis que a regulamentam, a RTP2 Portuguesa inova na apresentação da informação para as crianças, ao produzir e veicular o Diário $X S$, programa jornalístico destinado aos infantes dos oito aos doze anos. 


\section{Rádio e Televisão Portuguesa: o segundo canal}

A partir da década de 1990, o mercado audiovisual português foi reconfigurado em razão da concessão de licenças de funcionamento aos canais privados e da abertura do mercado para a publicidade. A emissora Rádio e Televisão Portuguesa (RTP), devido à abolição da taxa de licença que antes era paga pelos espectadores para financiar a programação - semelhante ao que ocorre ainda hoje no Reino Unido, com a BBC -, encontrava-se em agravada crise financeira, com enormes dívidas e sem condições de seguir custeando a programação.

Por causa da pressão realizada pelos dois novos canais privados, SIC e TVI, criados em 1992 e 1993, a RTP teve de reduzir o espaço destinado à publicidade e, de 1995 a 2001, o déficit financeiro foi de 50 milhões para 200 milhões de euros, enquanto as outras duas emissoras seguiam somando lucros.

Em 1995, já na tentativa de reverter a situação da RTP, o governo Socialista criou a "Comissão de Reflexão sobre o Futuro da Televisão", que era composta por membros do governo, da sociedade civil e especialistas em comunicação, que deveria discutir e traçar estratégias para a recuperação da emissora. As sugestões da comissão foram aceitas, porém, não implementadas. Em 2002, com o governo Social Democrata frente ao país, intencionou-se privatizar o segundo canal da RTP e manter apenas um canal público generalista. De acordo com Borges:

Essa medida foi muito contestada por diversos setores da sociedade, o que levou o governo a designar um Grupo de Trabalho para avaliar o funcionamento do serviço público de rádio e televisão. Os resultados apresentados em setembro de 2002 recomendavam a não privatização da RTP. A RTP1 deveria continuar como um canal público generalista e a RTP2 seria transformada num "serviço público alternativo aberto à sociedade civil no sentido de reforçar a diferença, os princípios universais, a coesão e a proximidade". (2011, p.242)

Em dezembro de 2002, após a apresentação do documento intitulado "Novas Opções para o Audiovisual" - que, entre outras coisas, salientava "a crise de identidade do setor em relação à estratégia, à organização e à integridade, principalmente devido ao incumprimento das obrigações de serviço público, à perda de audiências, aos altos custos de produção e de recursos humanos e à má gestão dos fundos públicos" (BORGES, 2011, p.242) - o segundo canal da RTP foi entregue à sociedade civil, com o objetivo de contribuir para o desenvolvimento da democracia e da sociedade, através da 
aproximação da televisão e dos cidadãos. Nessa nova configuração, os membros do terceiro setor seriam os responsáveis pelos conteúdos veiculados. Porém, o governo não propôs um modelo de funcionamento que permitisse aos cidadãos darem continuidade ao canal público sem prejuízo à qualidade.

Para regulamentar e implementar as mudanças necessárias, foi aprovada a Lei de Televisão $n^{\circ} 32 / 2003$, a qual definiu os deveres a serem cumpridos pelos canais

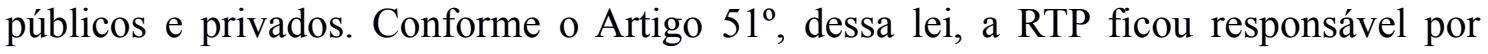
veicular programas com concessão especial. O canal, de acordo com a lei, deveria ser:

Especialmente vocacionado para a cultura, a ciência, a investigação, a inovação, a acção social, o desporto amador, as confissões religiosas, a produção independente, o cinema português, o ambiente e a defesa do consumidor e o experimentalismo audiovisual. Esse serviço de programas seria objeto de concessão autônoma, pelo prazo de oito anos, sob a titularidade da Rádio e Televisão de Portugal, SGPS, S.A. (Borges, 2011, p.243)

No contrato de concessão especial, cláusula de número cinco, decidiu-se pela abertura progressiva à sociedade civil, por meio de parcerias que deveriam contribuir para a construção de uma grade de programação com conteúdos especializados e de qualidade. Borges explica que "a abertura à sociedade civil possibilitou o acesso do público aos valores, às temáticas e às realidades que, em geral, não encontravam cobertura nos meios de comunicação", além de ofertar programas variados para públicos antes não contemplados.

Apesar disso, segundo Pereira (2007, p.24), o canal apresentava grandes dificuldades para conquistar o seu espaço no mercado televisivo e se aproximar do projeto idealizado, cinco anos após a reformulação. Porém, no que tange às crianças, a autora é mais otimista. De acordo com ela:

A televisão pública aproveita com frequência o seu segundo canal - RTP2 para a emissão de programação infanto-juvenil. Esta escolha deve-se, como confirmou a responsável por esta programação, às baixas quotas de audiência deste canal. Esta situação acaba por ser vantajosa para o público infantil, pois o facto de não pretender entrar na 'guerra de audiências' com os outros canais permite-lhe oferecer este tipo de programação no horário nobre das crianças e do próprio canal. (2007, p.25) 


\section{Jornalismo e Infância}

No universo da cidadania, o direto à informação constitui-se fundamental para o exercício pleno da função de cidadão. São as informações a que se tem acesso que permitem a tomada de decisões e as escolhas, na vida pública e privada. Segundo Miguel, o direito à informação é recoberto por um conjunto de prerrogativas diferentes, ainda que de fundamentos semelhantes:

Há, em primeiro lugar, o direito básico de conhecer os fatos do mundo. Há o direito de conhecer as diferentes correntes de pensamento que disputam a esfera pública. E há também o direito de conhecer os próprios direitos. Este último é a base de toda a cidadania consciente. O ser cidadão, na verdadeira acepção da palavra, implica entender a si mesmo e aos outros como sujeitos de direitos, estabelecendo com o Estado uma relação que não é de deferência, nem de alheamento. (2001, p.192)

Ainda que seja um direito inerente a todo o ser humano, o acesso à informação nem sempre é pleno. É-nos ofertado todos os dias uma gama diversa de mídias, formatos e discursos, porém, a questão do repertório e da linguagem ainda segrega e afasta, em muitos casos, o emissor da realidade do receptor.

O Jornalismo Infantil é um exemplo da necessidade de mediação linguística e cultural para que o público-alvo tenha a sua atenção capturada pelos emissores. No caso da comunicação feita para crianças, a tarefa é ainda mais difícil, pois, imersos em um mundo de facilidade e rapidez no alcance da informação por meio das tecnologias digitais, o público infanto-juvenil se apresenta bem mais complexo do que há algumas décadas. E o fato desse tipo de comunicação ser feita por adultos é a primeira dificuldade que se impõe para a qualidade do conteúdo, pois o jornalista adulto dificilmente consegue imergir no universo lúdico da infância.

Não compreendendo de fato as complexidades que envolvem o público a quem dirige o seu discurso, ele tende, em alguns casos, a infantilizar a sua fala, o que pouco contribui para a formação da criança. Outro caso problemático é o dos produtores de conteúdo que assumem a postura paternal e autoritária de quem decide com que tipo de informação a criança deve ser provida sem levar em conta as suas especificidades e a sua diversidade. O produtor de conteúdo, desse modo, toma para si a decisão do que é melhor para o infante, sem permiti-lo enxergar-se como parte do processo 
comunicativo. No artigo "Jornal para Crianças ou Jornalismo Infantil”, Ana Arruda explica, de acordo com Girardello, a importância da produção voltada para os infantes:

O fato é que a informação nunca esteve, tecnicamente, tão ao alcance de todos. A criança, através dela, entrou no mundo dos adultos. Acabou definitivamente a velha história de "isto não é conversa para criança; saia da sala, menino". [...] O universo da criança se ampliou, (como também o do adulto médio), mas continua a ser diverso do dos adultos. Ela entrou em nosso mundo, mas com uma visão sua, infantil, especial. [...] Quando tem seu interesse despertado para determinado assunto, a criança se dirige aos adultos - ou melhor, ao adulto de sua confiança - para se informar sobre o tema. [...] Existe, portanto, um público infantil para jornal. Interessado na informação. Mas precisando de uma informação dirigida especialmente para ele. (Arruda, op.cit., p.33)

As crianças enquanto cidadãs, portanto, têm o direito de receber informações que as permitam compreender o universo no qual estão inseridas e a se posicionar diante dele. Não é mais possível considerá-las como uma audiência passiva e acrítica. Não basta ofertar uma programação para elas. É preciso que os conteúdos sejam adequados.

\section{Diário XS - saber dá prazer}

O "Diário $X S$ - saber dá prazer" é um noticiário diário destinado a crianças de 8 a 12 anos, que se adéqua ao gênero jornalismo infantil, tratado anteriormente. É um programa noticioso, de cerca de cinco minutos de duração, veiculado pelo canal dois da RTP, às $17 \mathrm{~h} 40$ e às $19 \mathrm{~h} 45$, que apresenta notícias de Portugal e do mundo de forma didática e fácil de ser assimilada. Tem como formato uma série de notas cobertas, ou seja, reportagens feitas com sequencias de imagens gravadas ou fotografias cobertas por off gravado em estúdio, com a voz do locutor Luis Gaspar e poucas e curtas entrevistas.

De responsabilidade do jornalista Nelson Rodrigues, o telejornal para o público infantil e infanto-juvenil discorre sobre política, economia, cultura, meio ambiente, esporte, lazer, meteorologia e educação. A linguagem empregada é a coloquial e sempre há explicação dos termos mais complexos utilizados. Além disso, o Diário XS é veiculado também nas retransmissoras da RTP, como a RTP África e a RTP i América.

No dia 28 de agosto de 2012, por exemplo, o programa inicia com a cobertura de um encontro do grupo que negocia os rumos da crise portuguesa. A manchete resume a ideia principal da notícia: "os representantes da Troika estão de novo em Portugal para analisar as contas do governo". A seguir, de acordo com a proposta pedagógica do 
programa, o locutor explica o significado da expressão: “Troika é a palavra russa que significa trio e, nesse caso, é utilizada para falar dos três organismos que emprestaram dinheiro ao país: Fundo Monetário Internacional, Banco Central Europeu e Comissão Internacional" (Diário XS, 2012). No restante da reportagem, que tem cerca de um $1 \mathrm{~m}$ e 20s de duração, discorre-se sobre os desdobramentos da reunião, com a mesma linguagem clara e direta.

A reportagem a seguir é de relevância internacional e fala sobre o meio ambiente e suas intempéries. Nela, é explicada a diferença entre os fenômenos climáticos furacão, tufão e ciclone:

um tufão e um furacão são a mesma coisa, mas tem nomes diferentes consoante o sítio em que acontecem: chamam-se furacões quando iniciam do Oceano Atlântico ou no noroeste do Oceano Pacífico e tufões se nascerem no oceano índico ou no oeste do Pacífico. Noutras partes do Índico ou do Pacífico tem o nome de Ciclone. (Diário XS, 2012)

Segue com uma reportagem sobre ciência, com uma invenção para ajudar cegos a se locomoverem em locais públicos. Após, no eixo temático cultura, matéria sobre o festival cultural de Edimburgo, na Escócia, que recebe artistas de todo o mundo. Logo depois, uma reportagem sobre literatura e encerra com a previsão do tempo.

A linguagem, como é expresso na descrição inicial sobre o programa, disponível no website da emissora, é “extra simples” e o conteúdo é bastante resumido. Ainda que opte por trabalhar com a estrutura manchetada, com mais imagens cobertas por off e menos entrevistas, o Diário $X S$ não desliza na superficialidade, pois, como acredita Arruda, a informação ofertada serve de estímulo para despertar a curiosidade das crianças e adolescentes que, uma vez instigados, vão em busca de outras fontes de conhecimento para complementar aquilo que foi aprendido. Além disso, o programa é veiculado próximo ao horário nobre da televisão portuguesa (das $20 \mathrm{~h}$ às $23 \mathrm{~h}$ ), que é o período de maior audiência e quando, nos canais comerciais, são veiculados os telejornais tradicionais.

Para se aproximar ainda mais do seu público-alvo, o Diário $X S$ aposta não só em uma linguagem diferenciada dos padrões do telejornalismo para adultos, mas também na presença em rede social Facebook. Porém, não possui um perfil próprio. Está contido no perfil do programa Zig Zag, que aglutina toda a programação de cunho 
Estudos em Jornalismo e Mídia - Vol. 9 NN$^{\circ} 2$ - Julho a Dezembro de 2012 ISSNe 1984-6924

infantil da RTP2. Tanto no site da RTP2 quanto no Facebook, as edições antigas são disponibilizadas para a visualização, porém apenas a rede social permite a interação entre o público e os produtores. Nela, são postadas sugestões, dúvidas e pedidos dos telespectadores, além de informações sobre alterações no programa, por parte da emissora.

\section{Conclusão}

Durante o período de concessão especial da RTP2, de 2003 a 2006, houve uma grande aposta no público infantil, tendo havido um aumento de $4 \%$ no volume de programas e passando a representar $19 \%$ da grade de programação. Desde então, a RTP2 tem mantido um equivalente a sete horas diárias de programação infantil, divididas entre o período da manhã e do final da tarde até o horário nobre. É de destacar que a programação infantil é exibida no horário nobre enquanto nos outros canais da televisão aberta são exibidos os telejornais, tornando-se assim numa programação alternativa para as crianças.

Neste sentido, a aposta no jornalismo infantil, que não é nova, uma vez que o programa Quiosque, exibido de 2006 a 2008, também abordava temas jornalísticos e o programa PICA, exibido em 2010 também, garante a veiculação de informação de uma forma diferenciada, isto é, com um vocabulário e uma linguagem audiovisual adequados ao público. Além disso, o canal também faz uso das redes sociais, com a possibilidade das crianças interagirem com a produção, ainda que de forma rudimentar, nas página do Facebook. 


\section{Referências bibliográficas}

BORGES, G. 2011. A qualidade do canal 2:. Percursos teóricos e metodológicos da investigação. In: Gabriela Borges, G. \& Freire Filho, J. (org.). Estudos de televisão: diálogos Brasil-Portugal. Porto Alegre: Sulina, 2011, p. 240-274.

DIÁRIO XS, 2011. Lisboa: Diário XS, 28 de agosto de 2012. Telejornal infantil.

GIRARDELLO, Gilka. A produção cultural para crianças no ensino de graduação em comunicação. Portal Cultura Infância. Disponível em: $<$ http://www.culturainfancia.com.br/portal/index.php?

option=com content\&view=article \&id=154:a-producao-cultural-para-criancas-no-ensino-de-graduacaoem-comunicacao\&catid=46:midia-impressa\&Itemid=75>. Acesso em: 18 de agosto

MARTINS, Madô. Jornalismo para crianças. Observatório da Imprensa. Disponível em:

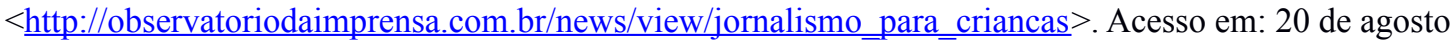

PEREIRA, Sara. A minha TV é um mundo: programação para crianças na era do ecrã global.

Lisboa: Campos das Letras, 2007. 156p.

PEREIRA, Sara. Por Detrás do Ecrã: Televisão para crianças em Portugal. Porto: Porto Editora, 2007. 212 p.

Este artigo e todo o conteúdo da Estudos em Jornalismo e Mídia estão disponíveis em http://www.periodicos.ufsc.br/index.php/jornalismo/index

Estudos em Jornalismo e Mídia está sob a Licença Creative Commons. 